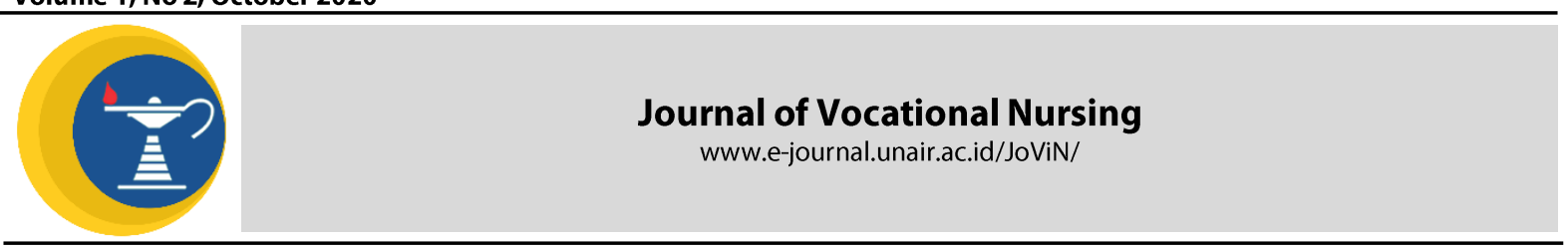

\title{
DESCRIPTION OF CHANGES IN INCREASED BODY WEIGHT IN KB PILL ACCEPTOR IN KELORARUM VILLAGE, TIKUNG SUBDISTRICT, LAMONGAN REGENCY
}

Fatkhiyatul Fitria', Ilkafah², Cucuk Rachmadi Prasetyo ${ }^{3}$

Case Study

1,2,3 DIII Nursing Study Program, Departement of Health, Faculty of Vocational Studies, Universitas Airlangga.

\section{ABSTRACT}

\begin{abstract}
Introduction: Patients with congestive heart failure usually have problems nursing chest pain. To reduce pain problems, there are several therapies that can be done, namely deep breath relaxation techniques, guide imagery techniques, and environmental management. The preferred therapy in this case is nonfaramcological, which is a deep breath relaxation technique. The purpose of this study was to provide acute pain nursing care for Congestive Heart Failure patients in the Heart Room at Dr. Soegiri Lamongan Hospital. Methods: Case study used to explore this study. Data collection is obtained through: interviews, observation, physical examination and documentation study. Analyzed case study results. From the discussion between literature review and case review, it is concluded that there is suitability from diagnosis to evaluation. Results: the case studies show an agreement between theoretical review and case review in patients. Evaluation of the Acute Pain nursing diagnoses, the problem was resolved on the third day. Conclusion: from the research conducted, found that deep breath relaxation technique is one of the effective nonpharmacological pain management methods to reduce pain.
\end{abstract}

\section{ARTICLE INFO}

Recived 24 October 2020

Accepted 27 October 2020

Online 29 October 2020

*Correspondence:

Fatkhiyatul Fitria

*Email:

fatkhiyatul042000@gmail.com

\section{Keywords:}

Acute Pain, Congestive Heart

Failure, Nursing Care

\section{INTRODUCTION}

Congestive Heart Failure (CHF) or commonly known as congestive heart failure is the inability of the heart to pump adequate blood to meet tissue needs for adequate oxygen and nutrition, causing a decrease in normal cardiac output and causing chest pain. Heart failure causes cardiac output to decrease, causes ventricular hypertrophy, myocardial shortening of LV filling, inadequate flow to the heart and brain, causes a high risk of decreased cardiac output, then decreased supply of $\mathrm{O} 2$ to the myocardium, increased myocardial tissue hypoxia, and causes changes in myocardial metabolism causing chest pain. Chest pain is a frequent complaint of Congestive Heart Failure patients 1.

Data from the World Health Organization (WHO) in 2013, showed 17.3 million people died from cardiovascular disorders in 2008. WHO said that more than 23 million people died each year with cardiovascular disorders. 2. In Indonesia alone, the prevalence of heart failure in 2013 was $0.13 \%$ or an estimated 229,696 people. The highest number of sufferers based on doctor's diagnosis was in East Java province as many as 54,826 people $(0.19 \%)$, while the lowest number of sufferers was found in Maluku province, namely 144 people $(0.02 \%)$. In the province of the special region of North Sumatra based on diagnosis / symptoms, the estimated number of people with heart failure was 26,819 people $(0.3 \%) 3$.

In addition, the results of the survey conductedKhasanah (2019), CHF incident on December 20, 2017 at Prof. dr. Margono Soekardjo Purwokerto obtained information that in 2015 there were 1647 cases and in 2016 there were 1524 cases and in 2017 there were 1493 patients. When viewed from 2015 to 2017 there was a decrease in the number of CHF patients in Prof. DR. Margono Soekarjo Purwokerto. However, the number of patients being treated at ICCU has increased, namely as follows: in 2015 there 43 cases, in 2016 there were 58 cases, and until November 2017 there were 52 cases. These results suggest that an increasing number of patients are experiencing life-threatening signs of CHF.

The impact experienced by clients with congestive heart failure or Congestive Heart 
Failure is experiencing fatigue and dyspnea which contribute to worsening quality of life 5 . In addition, if the pain in a congestive heart failure patient is not treated immediately, it will cause the patient to experience anxiety, immobilization, avoiding decreased attention span, stress and tension which will cause physical and psychological responses.6.

Based on the description above, how important it is to provide comfort to patients who experience pain, the authors are interested in conducting research / case studies on Nursing Care for Clients who experience Congestive Heart Failure (CHF) with pain nursing problems in the Heart Room of Dr. Soegiri Hospital, Lamongan.

\section{MATERIALS AND METHODS}

This type of research is qualitative research which includes an intensive study of one research unit, for example a client, family, group, community, or institution. The design of a case study depends on the circumstances of the case but still takes into account the research factors when this research was conducted in the Cardiac Room of Dr. SoegiriLamongan. Data collection techniques used in compiling the Final Project Report, are: interviews, observation, documentation. The data validity test emphasizes the validity and reliability. Data validity is a measure that shows the validity or validity of an instrument. So, validity testing refers to the extent to which an instrument can be used to measure what you want to measure. Meanwhile, the reliability of the data is the consistency or consistency of the tool in what size it is measuring. The participants in this case study were Mrs. $\mathrm{R}$ in the Heart Room of Dr. Soegiri Lamongan Hospital.

\section{RESULTS AND DISCUSSION}

\section{Assessment}

At the partial assessment stage, it was found that there was a correspondence between literature review and case review. The assessment is carried out according to the format in the literature review. The case study was carried out at Mrs.R with a Congestive Heart Failure in the Heart Room at Dr. Soegiri Lamongan Hospital.

The main complaint was found in conformity between case reviews and literature reviews, where in case reviews the main complaint felt by patients was chest pain. In the assessment of the history of the disease there is now a correspondence between a case review and a literature review. The client said pain in the left chest and radiating to the upper abdomen. Pain was felt since three days before entering the hospital. Pain felt like being stabbed, and pain felt when made to move and lessened when made to rest in a half-sitting position. Pain scale 6 . While literature review according to theory7, explained that the present medical history is an assessment that describes the main complaint using the PQRST. This is because pain must be assessed with the PQRST so that it can be assessed completely and accurately as experienced by the patient, to facilitate proper and appropriate handling.

In the assessment of the psycho, socio and spiritual history there is a correspondence between case reviews and literature reviews. In the case review, the client said he was sad with his current situation because the client had never been hospitalized. The client said the relationship with family, nurses, doctors and other patients was good. The client is cooperative with nursing actions. The client said that adherents of the Islamic religion are devout worshipers. According to theory8, explained that the psychological assessment of patients includes several dimensions that allow nurses to obtain clear perceptions of the patient's emotional, cognitive, and behavioral status. This is the role of nurses is very necessary to reduce the level of anxiety experienced by patients.

Therapy for clients is given analgesic and antibiotic injection. According to theory9, describes analgesic drugs in gastritis patients to treat pain and antibiotics to reduce infection. This is the role of nurses needed to help patients to take the right dose and time in consuming drugs to help the patient's recovery process.

\section{Nursing Diagnosis}

From the results of the case review, two diagnoses were found, namely: 1. Acute pain associated with heart tissue ischemia. (D.0077); 2. Activity intolerance related to physical weakness. (D.0056) In nursing care, there are two nursing diagnoses and the authors prioritize one of the two diagnoses, namely acute pain associated with heart tissue ischemia. The main priority diagnosis is acute pain, because this diagnosis can cause more serious health problems or the client can lose control against the body so that it can cause disruption in activities.

\section{Nursing Interventions}

From the literature review on nursing diagnoses, acute pain is associated with heart tissue ischemia, which is found in SIKI (Pain Management I.08238) which explains it consists of four domains. The first observation consists of: 1 . Identification of location, characteristics, duration, frequency, quality, intensity of pain, 2 . 
Identification of pain scales, 3. Identification of non-verbal pain responses, 4. Identification of factors that aggravate and relieve pain, 5 . Identify knowledge and beliefs about pain, 6. Identify cultural influences on pain response, 7 . Identify the effect of pain on quality of life, 8. Monitor the success of complementary therapies that have been given, 9. Monitor side effects of using analgesics. Second, therapeutic consists of: 1 . Provide non-pharmacological techniques to reduce pain, 2. Environmental control that aggravates pain, 3. Rest and sleep facilities, 4. Consider the types and sources of pain in choosing pain relief strategies, third is education consisting of : 1 . Describe the causes, periods and triggers of pain, 2. Explain pain relief strategies, 3. Instruct independent pain monitoring, 4. Instruct appropriate use of analgesics, 5. Teach nonpharmacological techniques to reduce pain. And the fourth is collaboration in providing analgesics, if needed.

Meanwhile, in a case review, only a few points are needed to help treat patients, namely: 1. Explain the causes and triggers of pain; 2 . Explain pain relief strategies; 3 . Identify the location, characteristics, duration, frequency, quality and intensity of pain; 4 . Identify the pain scale; 5 . Observation of TTV; 6 . Identification of factors that aggravate and reduce pain; 7 . Provide non-pharmacological techniques to reduce pain; 8. Collaboration of providing analgesics.

\section{Nursing Implementation}

The management of nursing actions is carried out in accordance with the plan that has been made, starting from November 25, 2019 to November 27, 2019 and all actions taken on patients are documented in nursing records. At this stage of implementation, the authors carry out nursing care in accordance with the plans that have been made on the intervention, namely the medical diagnosis of CHF. The author finds a match between literature review and case review. In case reviews when nursing actions were carried out, implementation was carried out in accordance with the intervention. The first day of nursing was carried out according to the intervention. In patients, the implementation carried out in its implementation is adjusted to the priority of action. In a case review nursing diagnoses Acute pain Explain the causes. The second to third day of nursing was carried out according to the intervention And the implementation of the third day was TTV observation every 8 hours, observation of the pain scale every 4 hours, giving the patient a comfortable and relaxed position. And on the third day the patient was discharged and then given a discharge planning. And during the implementation, the writer did not find any problems that could hinder the implementation.

\section{Nursing Evaluation}

In the evaluation, it was found that the agreement between the case review and literature review was found In the case review, after $3 \times 24$ hours of nursing action, the results were, the client said the pain was reduced, the general condition was enough to have a relaxed face, pain scale 2 , blood pressure: 170/80 $\mathrm{mmHg}$, pulse: $82 x$ / minute, RR: $20 \times /$ minute, S: $36.1 \mathrm{C}$. At the evaluation stage, there is a match between the literature review and the case review because the patient's condition has improved and the patient is discharged and given a discharge planning: Control at a predetermined time, take medication regularly and not be late, eat nutritious foods, maintain a healthy lifestyle and reduce stress.

According to10In the literature review, it is described that success in achieving nursing goals is assessed and is needed to modify nursing goals or interventions. The expected evaluation of the diagnosis is that the patient says the pain is reduced.

\section{CONCLUSION}

In the assessment stage, there is a correspondence between literature review and case review, starting from the main complaint, past medical history, current medical history, family medical history, psycho-socio-spiritual history, ADL (daily activities), physical examination and supporting examinations. There is agreement in the diagnosis of CHF patients, where in the case review and literature review there are two nursing diagnoses, namely acute pain associated with cardiac tissue ischaemia and activity intolerance related to physical weakness.

Nursing interventions with acute pain in CHF patients are structured according to priority nursing diagnoses. The implementation of nursing actions is carried out in accordance with the planning of the nursing diagnosis in accordance with the priorities that have been made, and nursing actions can be carried out properly. In

nursing evaluation problems can be resolved at the specified time, namely $3 \times 24$ hours. In case review at the 3rd day meeting, objectives are resolved.

\section{REFERENCES}

Akhmad AN. Quality of life of patients with congestive heart failure (CHF) based on demographic characteristics.J Nursing Soedirman. 2018; 11 (1): 27. 
Bachrudin M, Moh. Najib.Surgical Medical Nursing 1. 1st ed. South Jakarta: Ministry of Health of the Republic of Indonesia; 2016.

Basic Health Research. Heart Health Situation. South Jakarta: Ministry of Health of the Republic of Indonesia; 2013.

Khasanah S. Differences in Oxygen Saturation and Respiration Rate of Congestive Heart Failure Patients on Changes in Position. J Nursing Science Med Surgery. 2019; 2 (1): 1.

Muttaqim A, Sari K. Gastrointestinal Disorders: Nursing Care Applications. Jakarta: Salemba Medika; 2011.

Nursalam 2014. D08120010-001-4-Nur-KConcept-And-Application-MethodologyResearch-Sciences-Nursing-Ed-2_LibraryStikes-Pekajangan-2014.Pdf. 2014.
Purba L. Compliance Case Study Oxygenation Needs with Deep Breath Relaxation Techniques in Congestive Heart Failure Patients at Tk li Putri Hijau Hospital in Medan in 2016. J Ris Hesti Medan. 2016; 1 (2): 118.

Pratintya DA. Warm CompressReducing Osteortriti Joint Pain in the Elderly. J Midwifery and Nursing. 2014: 10.

Utami adinna dwi, Kartika imelda rahmayunia. Complemenary Therapies To Reduce Pain in Gastritis Patients:REAL J. 2018; 1 (3): 123-132.

WHO. Prevntion of Cardiovascular Disease. In: Epidemioogy Sub Region AFRD and AFRE. ;2013 